\title{
Simultaneous and Trace Level Quantification of Five Potential Genotoxic Impurities in Ranolazine Active Pharmaceutical Ingredient Using LC-MS/MS
}

\author{
Kartheek Srinivas Chidella ${ }^{1}$, Vijaya Bharathi Dasari ${ }^{2}$, Jayashree Anireddy ${ }^{1}$ \\ ${ }^{1}$ Center for Chemical Sciences and Technology, Institute of Science and Technology, Jawaharlal Nehru Technological University, \\ Hyderabad, Telangana, India \\ ${ }^{2}$ Aurobindo Pharma Laboratory Research Center II, Hyderabad, Telangana, India \\ Email: kartheeksrinivas2008@gmail.com
}

How to cite this paper: Chidella, K.S., Dasari, V.B. and Anireddy, J. (2021) Simultaneous and Trace Level Quantification of Five Potential Genotoxic Impurities in Ranolazine Active Pharmaceutical Ingredient Using LC-MS/MS. American Journal of Analytical Chemistry, 12, 1-14. https://doi.org/10.4236/ajac.2021.121001

Received: December 9, 2020

Accepted: January 12, 2021

Published: January 15, 2021

Copyright $\odot 2021$ by author(s) and Scientific Research Publishing Inc. This work is licensed under the Creative Commons Attribution International License (CC BY 4.0).

http://creativecommons.org/licenses/by/4.0/

(c) (i) Open Access

\begin{abstract}
Highly sensitive liquid chromatography-tandem mass spectrometry (LC-MS/MS) method has been developed for the simultaneous determination of five potential genotoxic impurities in ranolazine active pharmaceutical ingredient. Chromatographic separation achieved using Poroshell C18 PFP $150 \times 3.0 \mathrm{~mm}$ $2.7 \mu$ column and $0.1 \%$ formic acid in water as Mobile phase A and $0.1 \%$ formic acid in methanol as mobile phase $\mathrm{B}$ using gradient elution and a flow rate of $0.4 \mathrm{ml} / \mathrm{min}$ with a run time of 18 minutes. Mass spectrometric conditions were optimized using electrospray ionization in positive mode. Method shows excellent linearity from $0.05-5.0 \mathrm{ppm}$ of the ranolazine test concentration for all the five impurities. The correlation coefficient was observed greater than 0.99 . Satisfactory recoveries were observed for all the five impurities within the range of $102.9 \%-112.3 \%$. Method has been validated as per ICH recommended guidelines with a LOQ of $0.15 \mathrm{ppm}$ achieved. The developed method was able to quantify all the five impurities at a concentration level of $1 \mathrm{ng} / \mathrm{ml}$ ( $0.5 \mathrm{ppm}$ with respect to $2 \mathrm{mg} / \mathrm{ml}$ ranolazine).
\end{abstract}

\section{Keywords}

Genotoxic Impurities, LC-MS/MS, Sensitive

\section{Introduction}

Pharmaceutical impurities are the unwanted chemicals that remain with active pharmaceutical ingredients which may arise during synthesis or may be derived 
from sources such as starting materials, intermediates, reagents, solvents, catalysts, reaction by-products and can also form due to degradation of API. Potential genotoxic impurities (PGI) are the impurities that have potential to interact with genetic material and can cause DNA alteration or damages. During toxicological assessment, these PGIs are proven to be genotoxic with established data for carcinogenicity. Several regulatory agencies like United States Food and Drug Administration (USFDA) [1] [2] and European Medicines Agency (EMEA) [3] and very recently International council of Harmonization of technical requirements for pharmaceuticals use (ICH) [4] have released guidelines regarding the regulatory issues related to the presence of genotoxic impurities in new drug substances and products. Threshold of toxicological concern refers to a threshold exposure level of $1.5 \mu \mathrm{g} /$ day was also established. It is of utmost importance to quantify these genotoxic impurities at trace levels which would require highly sensitive analytical techniques like LC-MS/MS to establish the safety of the drug product for human use.

Ranolazine, a piperazine derivative sold under the trade name Ranexa, is a well-tolerated medication that selectively inhibits the late sodium current. Ranolazine is currently approved in the United States and Europe as a second-line agent in the management of chronic stable angina pectoris (CSAP) [5] One study also demonstrated that ranolazine was an effective anti-anginal in patients with stable coronary artery disease despite maximal doses of amlodipine [6]. In addition, ranolazine decreases angina episodes and increases exercise tolerance in individuals taking concomitant atenolol, amlodipine or diltiazem. Ranolazine indirectly prevents the calcium overload that causes cardiac ischemia [7].

The aim of the current research work is to quantify five potential genotoxic impurities observed in ranolazine drug substance at trace levels. During extensive literature survey for analytical techniques for the determination of impurities in ranolazine, there were several chromatographic methods reported which are stability indicating for ranolazine drug substance and formulation [8] [9] [10] [11]. Several methods were reported for determination of ranolazine in bulk and tablet dosage form [12] [13] and some LC-MS/MS methods reported for determination of ranolazine in biological matrices [14] [15] [16]. One LC-MS/MS method was reported for the determination of single genotoxic impurity 2-[(2methoxy phenoxy) methyl] oxirane content in ranolazine drug substance [17]. There were no data in literature available for LC-MS/MS method for simultaneous determination of five genotoxic impurities in ranolazine. However, based on the results obtained from computational structural analysis for mutagenicity alerts, the possible genotoxic impurities were procured. Considering the maximum allowable dosage, the GTI concentration must be controlled in ranolazine at concentration lower than $0.5 \mathrm{ppm}$. In this paper, we present the highly sensitive LCMSMS method development for the determination of all the five potential genotoxic impurities namely 2,6,-Dimethyl aniline, Related compound A, ((2,6-Dimethyl)amino carbonyl methyl) chloride, Chlorohydrin impurity and 
Dichloro impurity in Ranolazine which are represented in Figure 1. The validation of the method was performed with respect to specificity, Limit of detection (LOD), Limit of quantification (LOQ), linearity, repeatability, accuracy and robustness in accordance with ICH guidelines.<smiles>COc1ccccc1OCC(O)CN1CCN(CC(=O)Nc2c(C)cccc2C)CC1</smiles>

Molecular Formula: $\mathrm{C}_{24} \mathrm{H}_{33} \mathrm{~N}_{3} \mathrm{O}_{4}$ Monoisotopic Mass: 427.247107 Da

(a)<smiles>Cc1cccc(C)c1N</smiles>

Molecular Formula: $\mathrm{C}_{8} \mathrm{H}_{11} \mathrm{~N}$ Monoisotopic Mass: 121.089149 Da

(b)<smiles>COc1ccccc1OCC1CO1</smiles>

Molecular Formula: $\mathrm{C}_{10} \mathrm{H}_{12} \mathrm{O}_{3}$ Monoisotopic Mass: $180.078644 \mathrm{Da}$

(d)<smiles>Cc1cccc(C)c1NC(=O)CCl</smiles>

Molecular Formula: $\mathrm{C}_{10} \mathrm{H}_{12} \mathrm{CINO}$ Monoisotopic Mass: 197.060742 Da

(c)<smiles>COc1ccccc1OCC(O)CCl</smiles>

Molecular Formula: $\mathrm{C}_{10} \mathrm{H}_{13} \mathrm{ClO}_{3}$ Monoisotopic Mass: 216.055322 Da

(e)<smiles>Cc1cccc(C)c1NC(=O)C(Cl)Cl</smiles>

Molecular Formula: $\mathrm{C}_{10} \mathrm{H}_{11} \mathrm{Cl}_{2} \mathrm{NO}$

Monoisotopic Mass: 231.021769 Da

(f)

Figure 1. Structures of Ranolazine API (a), 2,6,-Dimethyl aniline (b), ((2,6-Dimethyl)amino carbonyl methyl) chloride (c), Related compound A (d), Chlorohydrin impurity (e) and Dichloro impurity (f). 


\section{Experimental}

\subsection{Reagents and Chemicals}

All the solvents and reagents used are of LC-MS grade with the highest purity of $>99.8 \%$. Water, Acetonitrile and Methanol were purchased from Honeywell (Charlotte, NC, USA). Formic acid was purchased from Fluka. Ranolazine and its five potential genotoxic impurities were procured from PS3 labs LLP, Hyderabad, India.

\subsection{Mobile Phase Preparation}

Mobile phase A was prepared by addition of $1 \mathrm{ml}$ of formic acid in $1000 \mathrm{ml}$ of water and mobile phase B was prepared by addition of $1 \mathrm{ml}$ of formic acid in $1000 \mathrm{ml}$ of Methanol. Both the mobile phases were degassed and stored at ambient temperature for further use. Fresh mobile phases prepared before each set of analysis.

\subsection{Preparation of Sample and Standard Solutions}

Weighed accurately $10 \mathrm{mg}$ each of all five impurities and transferred in $10 \mathrm{ml}$ volumetric flasks further dissolved in $100 \%$ acetonitrile to obtain final concentration of $1000 \mu \mathrm{g} / \mathrm{ml}$. A $10 \mu \mathrm{g} / \mathrm{ml}$ mixture of 5 impurities were further prepared by adding appropriate volumes of each stock and diluted with $80 \%$ Acetonitrile solution. Further dilution to $1 \mu \mathrm{g} / \mathrm{ml}$ mixture was performed. A series of calibration standards were prepared from $1 \mu \mathrm{g} / \mathrm{ml}$ to obtain the final concentrations of $10,5,2.5,1,0.5,0.25$ and $0.1 \mathrm{ng} / \mathrm{ml}$.

Spike solutions for recovery experiment were prepared by weighing accurately $20 \mathrm{mg}$ of Ranolazine drug substance in $10 \mathrm{ml}$ volumetric flask and then add appropriate volume of 5 impurity mix stock to obtain a concentration of $1 \mathrm{ng} / \mathrm{ml}$ $(0.5 \mathrm{ppm})$ and $0.3 \mathrm{ng} / \mathrm{ml}(0.15 \mathrm{ppm})$ with respect to test concentration of 2 $\mathrm{mg} / \mathrm{ml}$ of ranolazine. Experiment was performed in triplicate to ensure the repeatability.

\subsection{LC-MS/MS Operating Conditions}

Chromatographic analysis performed using 1290 Infinity II (Agilent technologies., Santa Clara, CA) UHPLC equipped with a binary pump, multisampler and diode array detector coupled with an Agilent 6470 (Agilent technologies., Santa Clara, CA) LC-MS/MS triple quadrupole with Agilent Jet stream (AJS) Electrospray Ionization interface. Chromatographic separation achieved on Poroshell C18 PFP $150 \times 3.0 \mathrm{~mm} 2.7 \mu$ column (Agilent technologies., Santa Clara, CA) and $0.1 \%$ formic acid in water as Mobile phase $\mathrm{A}$ and $0.1 \%$ formic acid in methanol as mobile phase B using gradient elution at a flow rate of $0.4 \mathrm{ml} / \mathrm{min}$ with a run time of 18 minutes. The column oven temperature maintained at $40^{\circ} \mathrm{C}$ and the autosampler temperature maintained at $10^{\circ} \mathrm{C}$ with a injection volume of 10 $\mu \mathrm{l}$. The gradient program used as follows (time in $\mathrm{min} / \% \mathrm{~B}$ ): 0.00/2, 2.00/2, 
7.00/50, 10.00/90, 14.00/90, 14.1/2,18.00/2.

Mass spectrometric conditions were optimized in ESI positive mode using MRM mode of acquisition for all the five impurities in the form of protonated molecular ions $(\mathrm{M}+\mathrm{H})^{+}$at $\mathrm{m} / \mathrm{z} 122.1,181.1,198.0,217.1,232,0$ respectively for 2,6 Dimethyl aniline, Related compound A, ((2,6-Dimethyl)amino carbonyl methyl) chloride, Chlorohydrin impurity and Dichloro impurity. Ionization source was operated with a capillary voltage $4500 \mathrm{~V}$, Nozzle voltage $1500 \mathrm{~V}$, Drying gas temperature $300^{\circ} \mathrm{C}$, Drying gas flow $121 / \mathrm{min}$, Nebulizer pressure $35 \mathrm{psi}$, Sheath gas temperature $350^{\circ} \mathrm{C}$, Sheath gas flow $10 \mathrm{l} / \mathrm{min}$ respectively. All parameters of LC and MS were controlled using Agilent Mass Hunter software version 10.1.

\subsection{Method Validation}

We could successfully validate the developed method in terms of Specificity, reproducibility, linearity, LOD, LOQ, robustness and solution stability. All the validation parameters conducted using ICH guidelines. Initially to establish the sensitivity of the method individual solutions of the impurities injected at absolute concentrations of $0.3 \mathrm{ng} / \mathrm{ml}(0.15 \mathrm{ppm}$ wrt ranolazine $2 \mathrm{mg} / \mathrm{ml}$ test concentration) and obtained the $\mathrm{S} / \mathrm{N}$ ratio values. Further repeatability of the method was established at $1 \mathrm{ng} / \mathrm{ml}(0.5 \mathrm{ppm}$ wrt ranolazine $2 \mathrm{mg} / \mathrm{ml}$ test concentration) by injecting six consecutive injections from the same vial. Next, the linearity of the method was evaluated from $0.1 \mathrm{ng} / \mathrm{ml}$ to $10 \mathrm{ng} / \mathrm{ml}$ using seven different concentration levels. To calculate slope, intercept and regression coefficient values least square linear regression was employed. Recovery experiment was performed in triplicate at two different concentration levels of $1 \mathrm{ng} / \mathrm{ml}(0.5 \mathrm{ppm}$ wrt test) and LOQ (0.15 ppm wrt test) to establish the efficiency. Specificity of the developed method was assessed in presence of ranolazine API. Robustness of the method was tested by altering the mobile phase composition and column temperature conditions. Further, the analysis of solutions at different time intervals was performed to establish the solution stability of all the five impurities.

\section{Results and Discussion}

\subsection{Chromatographic Method Development}

This study was conducted to develop highly sensitive and selective analytical method that could separate and quantify all the five potential genotoxic impurities in Ranolazine API.

To achieve good peak shapes and critical separation between ranolazine and impurities, several mobile phase $\mathrm{pH}$ and gradient conditions were evaluated but $0.1 \%$ formic acid provided the better peak shapes and sensitivities. Few of the columns tested for separation between impurities and ranolazine. In Poroshell $\mathrm{HPH} 150 \times 4.6 \mathrm{~mm} 2.7 \mu$ column, there is coelution of impurities and API observed with initial elution of API. When we tried with Poroshell PFP $150 \times 3.0$ $\mathrm{mm} 2.7 \mu$ column to increase the separation and induce selectivity, we could see 
good separation between API and all five impurities. Both the methanol and acetonitrile were evaluated for mobile phase B and concluded with $0.1 \%$ formic acid in Methanol due to better separation efficiency. Different flow rates were checked and concluded with $0.4 \mathrm{ml} / \mathrm{mi}$. Different column temperatures were checked and concluded with $40^{\circ} \mathrm{C}$. The retention times of impurities Dimethyl aniline, Related compound A, ((2,6-Dimethyl)amino carbonyl methyl) chloride, Chlorohydrin impurity and Dichloro impurity were observed to be 7.74, 10.56, $10.22,11.00,11.002 \mathrm{~min}$ respectively and ranolazine eluted at $9.435 \mathrm{~min}$. Representative chromatograms for standard and spike samples with all five impurities provided in Figure 2 \& Figure 3.

\subsection{Optimization of MS/MS Parameters}

Mass spectrometric conditions optimization aimed at developing simple, selective, highly sensitive and robust method for the determination of five impurities in Ranolazine API. $1.0 \mu \mathrm{g} / \mathrm{ml}$ impurity mix solution was used to carry out MSMS method development. During initial stages of development positive mode ionization was found to be more sensitive than negative mode due to the nature of the impurities, limiting the method development to positive ionization only. Compound dependent parameters like capillary voltage (V), Nozzle voltage (V) and fragmentor voltage $(\mathrm{V})$ were optimized for each individual impurity to obtain the desired response for parent ions which are captured in Table 1. Further collision energies were optimized by checking with different Collison cell voltages to establish sensitive and reproducible MRM transitions for all the five impurities. The MS/MS spectra for all the five impurities at different collision energies were captured in Figures 4-8.

\section{Method Validation}

The optimized method was successfully validated as per ICH recommended guidelines and established all the critical parameters required to show the efficiency of the method.

Table 1. Optimized MS/MS parameters for all the five potential genotoxic impurities in positive ion mode.

\begin{tabular}{cccccc}
\hline S. No & Name of the Impurity & $\begin{array}{c}\text { Precursor ion } \\
(\mathrm{m} / \mathrm{z})\end{array}$ & $\begin{array}{c}\text { Production } \\
(\mathrm{m} / \mathrm{z})\end{array}$ & $\begin{array}{c}\text { Fragmentor } \\
\text { voltage }(\mathrm{V})\end{array}$ & $\begin{array}{c}\text { Collison } \\
\text { energy (V) }\end{array}$ \\
\hline 1 & Dimethyl aniline & 122.1 & 105.1 & 80 & 16 \\
2 & Related compound A & 181.1 & 125.1 & 65 & 6 \\
3 & $\begin{array}{c}\text { Dimethyl phenyl } \\
\text { aminocarbonyl chloride }\end{array}$ & 198 & 122 & 70 & 20 \\
4 & $\begin{array}{c}\text { Chlorohydrin impurity } \\
5\end{array}$ & 217.1 & 163 & 80 & 6 \\
\hline
\end{tabular}




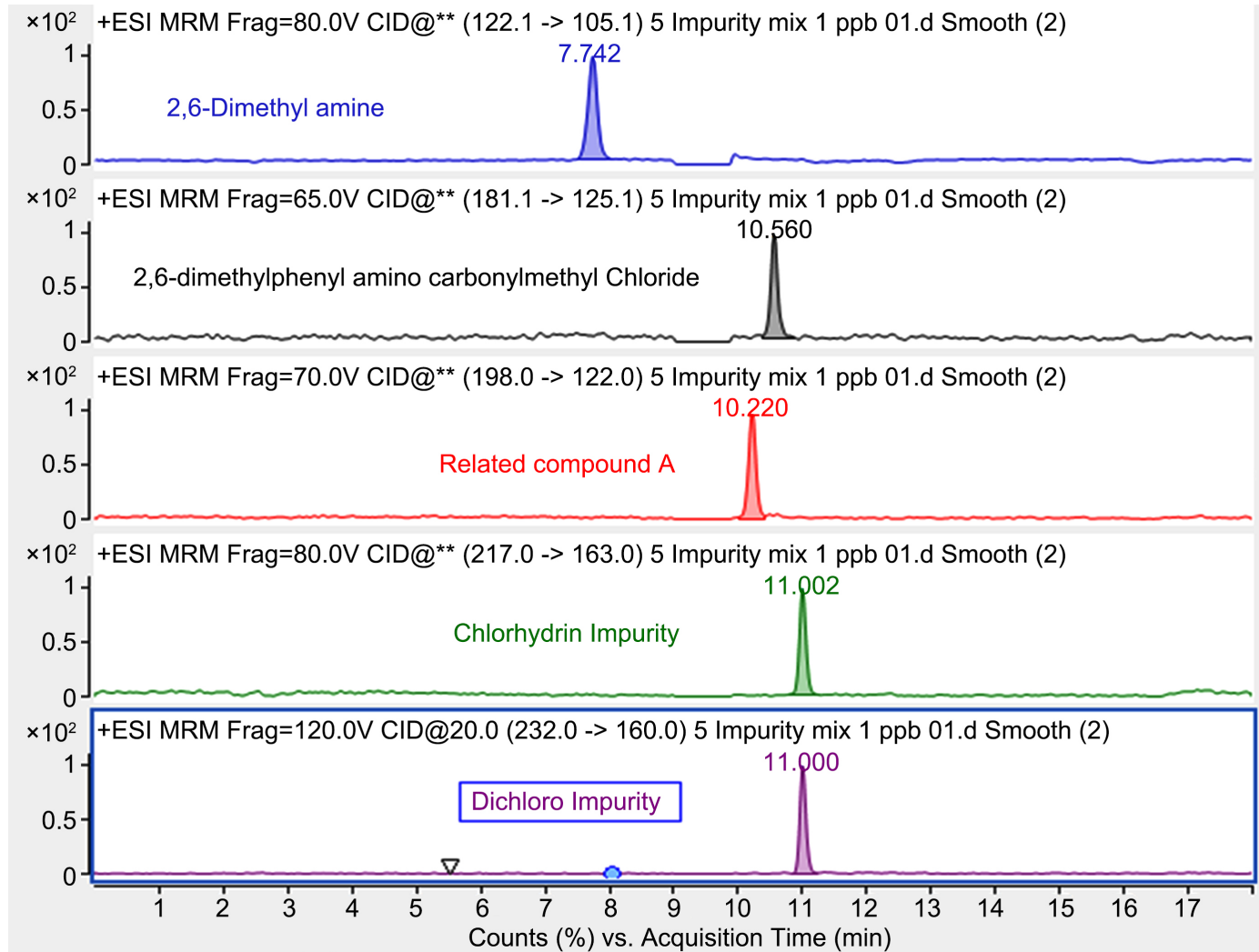

Figure $2.1 \mathrm{ng} / \mathrm{ml}(0.5 \mathrm{ppm})$ standard chromatogram for all the five potential genotoxic impurities.

$\times 10^{2}$ DAD1-A:Sig=280.0.4.0 Ref=off Ranolazine $1 \mathrm{ppb}$ spike 01.d

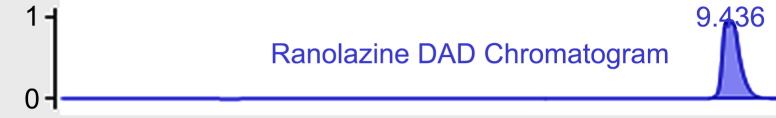

$\times 10^{2}+\mathrm{ESI}$ MRM Frag=80.0V CID@** $(122.1$-> 105.1) Ranolazine 1 ppb spike 01.d Smooth

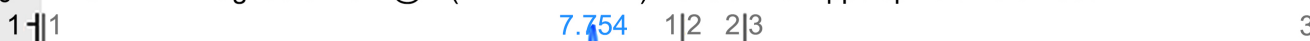

0

$\times 10^{2}$ +ESI MRM Frag=65.0V CID@** (181.1 -> 125.1) Ranolazine 1 ppb spike 01.d Smooth

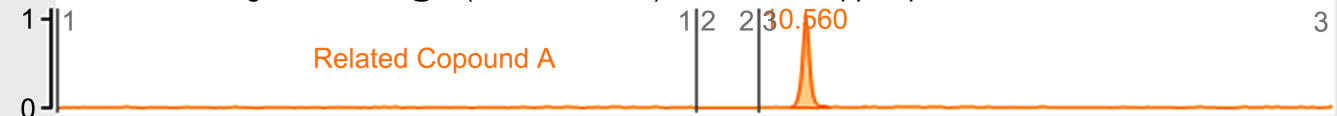

$\times 10^{2}+$ ESI MRM Frag=70.0V CID@ ${ }^{* *}(198.0$-> 122.0) Ranolazine 1 ppb spike 01.d Smooth

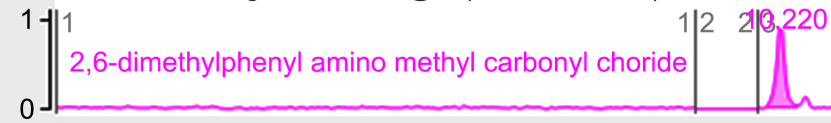

$\times 10^{2}+$ ESI MRM Frag=80.0V CID@ ${ }^{* *}(217.1$-> 163.0) Ranolazine 1 ppb spike 01.d Smooth

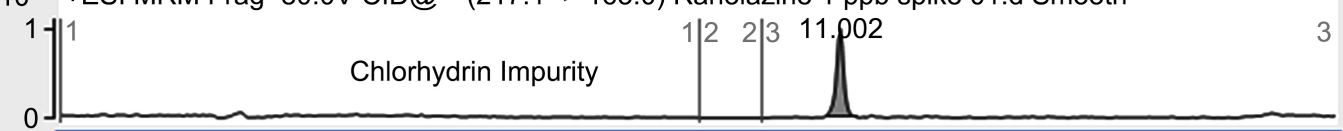

$\times 10^{2}+$ +ESI MRM Frag=120.0V CID@20.0 (232.0 -> 160.0) Ranolazine 1 ppb spike 01.d Smooth

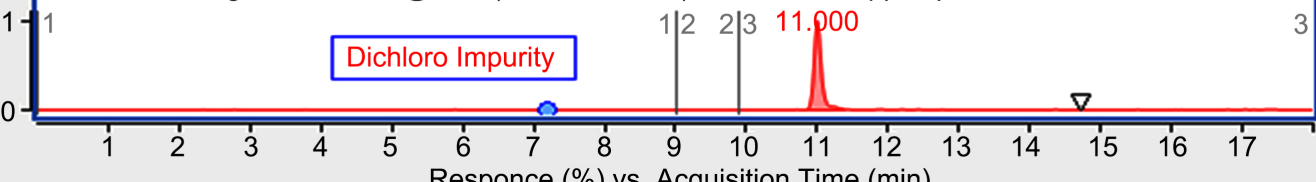

Figure 3. $1 \mathrm{ng} / \mathrm{ml}(0.5 \mathrm{ppm})$ spike chromatogram for all the five potential genotoxic impurities. 


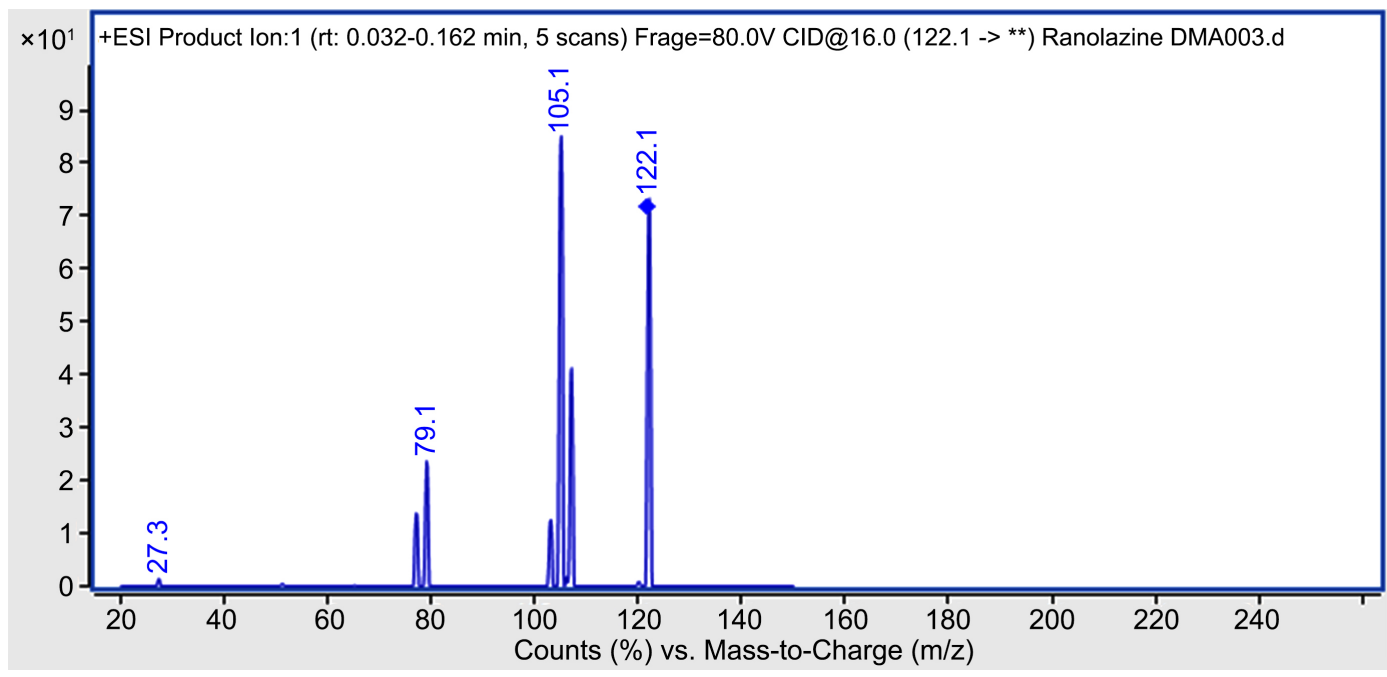

Figure 4. MS/MS spectra of dimethyl amine.

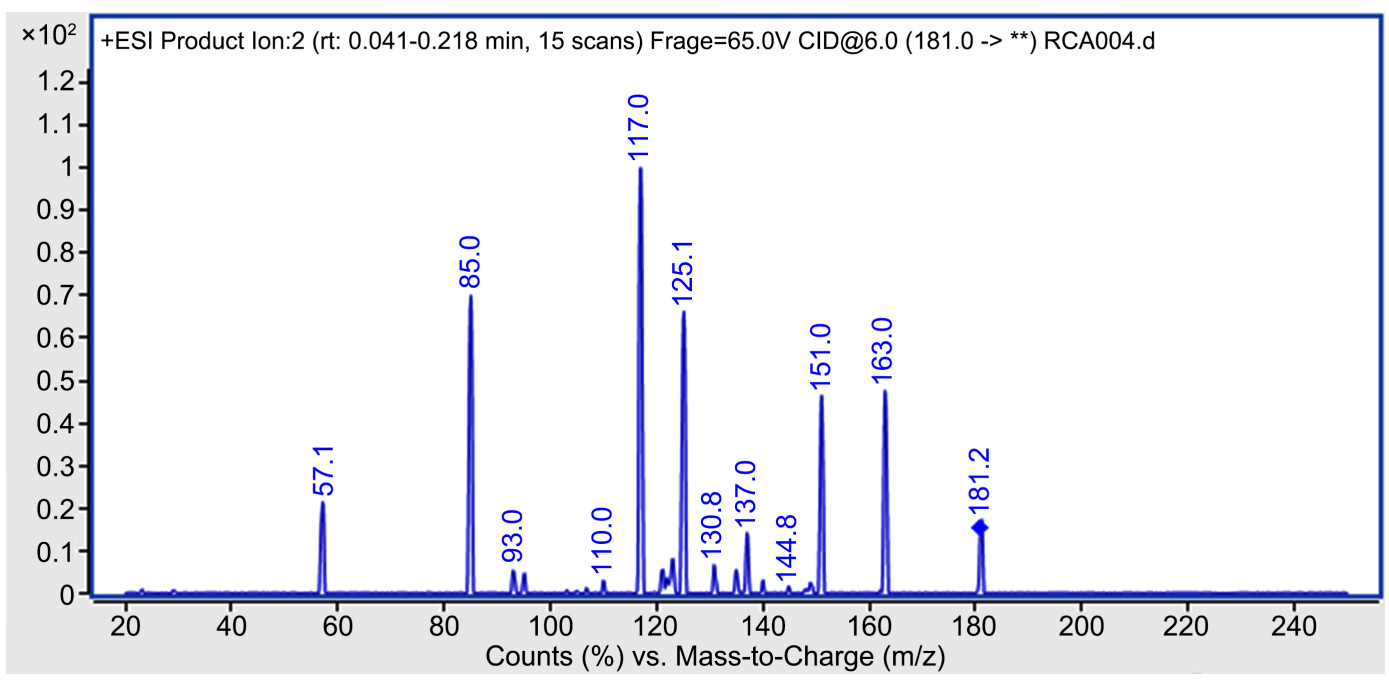

Figure 5. MS/MS spectra of related compound A.

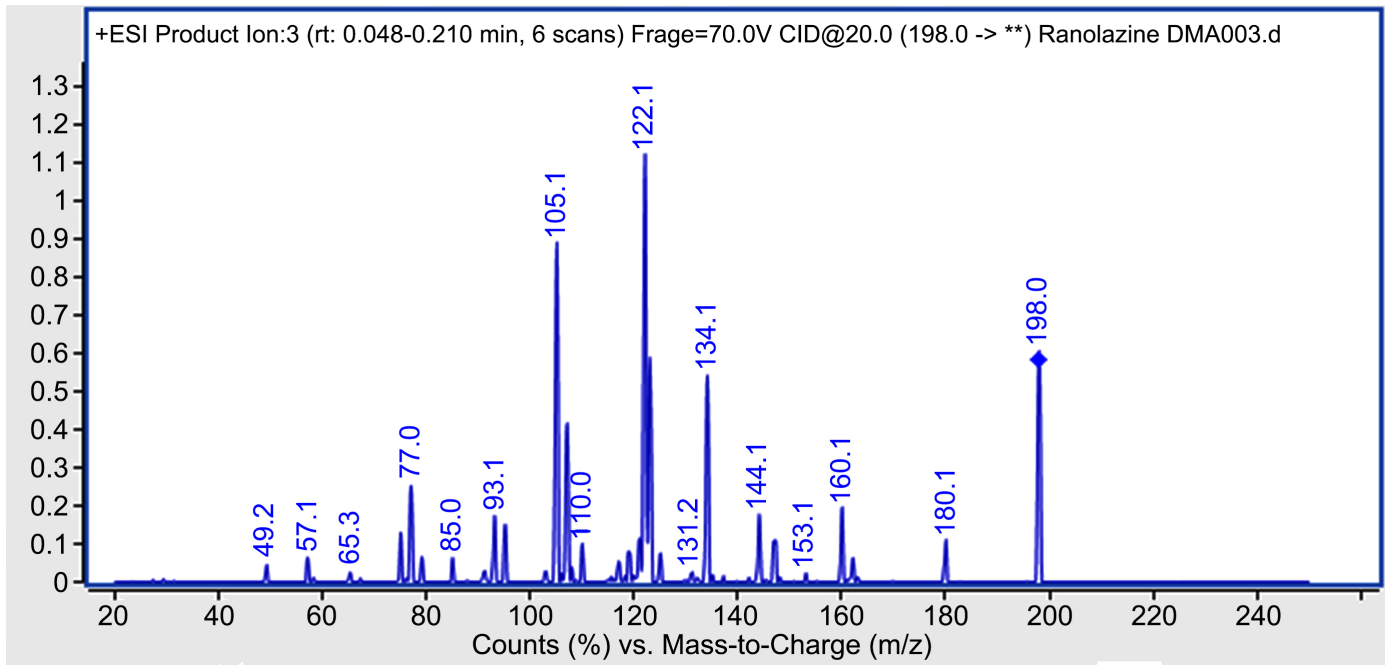

Figure 6. MS/MS spectra of Di methyl phenyl aminocarbonyl chloride impurity. 


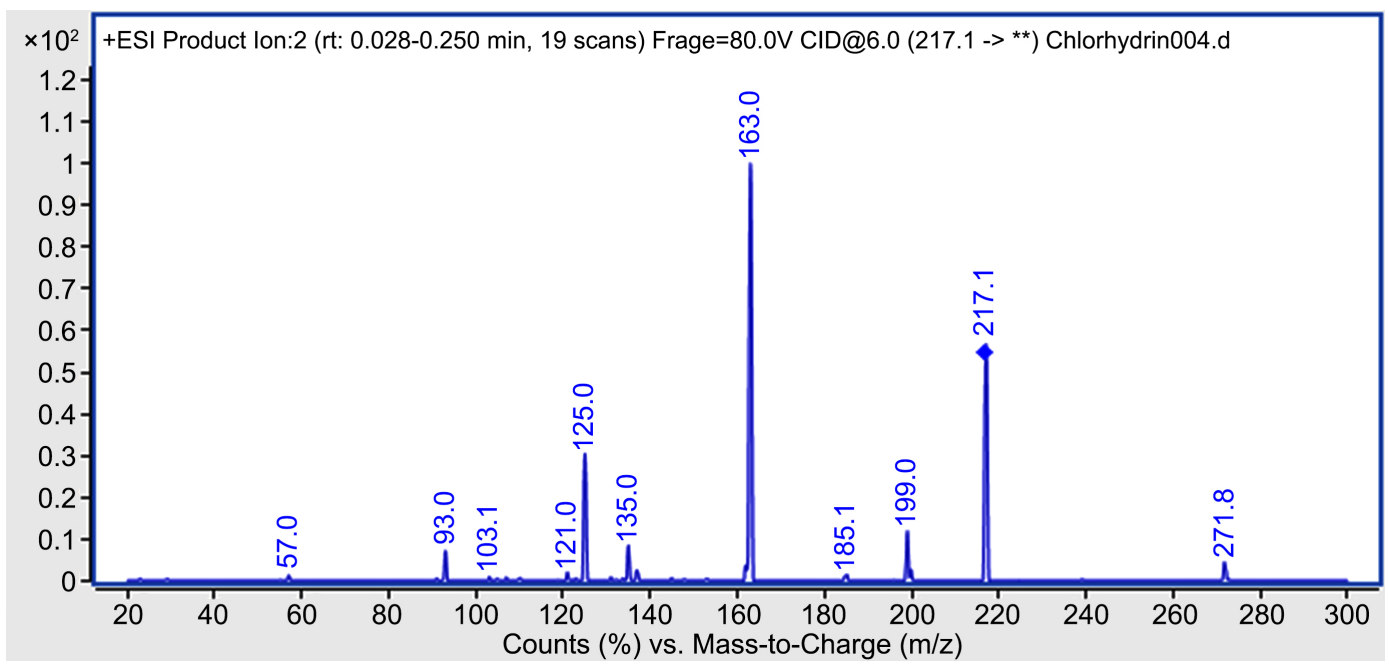

Figure 7. MS/MS spectra of chlorhydrin impurity.

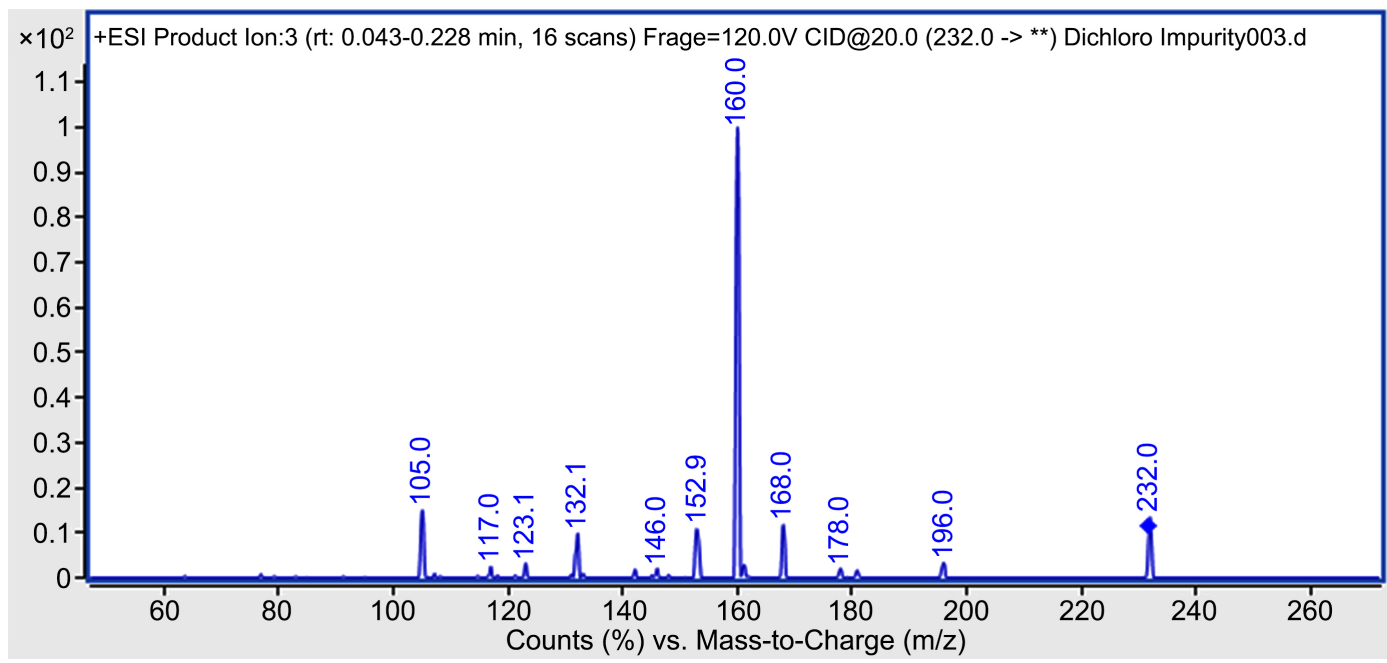

Figure 8. MS/MS spectra of dichloro impurity.

\subsection{Specificity}

A single ranolazine with five impurity mix solution was prepared at specification level in the diluent. The spiked ranolazine solution was then subjected to LCMS/MS analysis. The obtained results have shown that there is no interference of ranolazine API with all the five impurities Dimethyl aniline, Related compound A, ((2,6-Dimethyl)amino carbonyl methyl) chloride, Chlorohydrin impurity. The chromatogram acquired was captured in Figure 2.

\subsection{Linearity}

The linearity of the method was established from $0.1 \mathrm{ng} / \mathrm{ml}$ to $10 \mathrm{ng} / \mathrm{ml}(0.05-5$ $\mathrm{ppm}$ ) for all five genotoxic impurities. The slope, intercept and regression coefficient values were derived using least squares linear regression analysis of average peak areas versus concentration of impurities. Good correlation between peak areas and concentrations of impurities observed as can be seen in Table 2. 


\subsection{LOD and LOQ}

The LOQ and LOQ values for all the five impurities were determined based on $\mathrm{S} / \mathrm{N}$ ratios of 10.0 and 3.0 respectively, by injecting known standard concentrations and the results are captured in Table 2. Peak to peak algorithm used to derive the $\mathrm{S} / \mathrm{N}$ ratio values for all the five impurities. Reproducibility and recovery were also evaluated at LOQ level using triplicate injections.

\subsection{Accuracy and Recovery}

Accuracy referred as deviation from linearity was evaluated by injecting impurity mixture from LOQ which is $30 \%$ of specification limit and on 10 times the specification limit. The acceptance criteria for accuracy is between $70 \%-130 \%$ for such a low concentration range. Accuracy values were observed at all levels for all the impurities within 10\% which are well within the required acceptance criteria. The accuracy (as recovery) was further evaluated by standard addition method in triplicate at two concentrations at $0.15 \mathrm{ppm}$ and $0.5 \mathrm{ppm}$ levels in ranolazine API. The acceptance criteria for recovery is $80 \%-120 \%$. The percentage recoveries for all the impurities are presented in Table 3 .

Table 2. Linearity ranges, Correlation Coefficients, Signal to Noise ratios of LOQs and LODs for all the five impurities.

\begin{tabular}{|c|c|c|c|c|c|}
\hline \multirow{2}{*}{ S. No } & \multirow{2}{*}{ Name of the Impurity } & \multirow{2}{*}{$\begin{array}{c}\text { Linearity } \\
\text { Range (ppm) }\end{array}$} & \multirow{2}{*}{$\begin{array}{c}\text { Correlation } \\
\text { coefficient }\left(\mathrm{R}^{2}\right)\end{array}$} & \multicolumn{2}{|c|}{$\begin{array}{c}\mathrm{S} / \mathrm{N} \text { ratio } \\
\text { (Peak to Peak basis) }\end{array}$} \\
\hline & & & & LOQ & LOD \\
\hline 1 & Dimethyl aniline Impurity & $0.05-5$ & 0.9921 & 19.83 & 7.16 \\
\hline 2 & RCA Impurity & $0.05-5$ & 0.9925 & 13.38 & 4.83 \\
\hline 3 & $\begin{array}{l}\text { Di methyl phenyl aminocarbonyl } \\
\text { chloride impurity }\end{array}$ & $0.05-5$ & 0.9985 & 15.05 & 5.25 \\
\hline 4 & Chlorohydrin impurity & $0.05-5$ & 0.9978 & 17.66 & 9.09 \\
\hline 5 & Dichloro Impurity & $0.05-5$ & 0.9985 & 45.66 & 14.82 \\
\hline
\end{tabular}

Table 3. Recoveries of all the five impurities at LOQ and $0.5 \mathrm{ppm}$.

\begin{tabular}{cccc}
\hline S. No & Name of the Impurity & Recovery at LOQ & Recovery at 0.5 ppm \\
\hline 1 & Dimethyl aniline Impurity & 116.1 & 106.4 \\
2 & RCA Impurity & 102.8 & 112.3 \\
3 & $\begin{array}{r}\text { Di methylphenyl aminocarbonyl } \\
\text { chloride impurity }\end{array}$ & 103.0 & 102.9 \\
4 & Chlorohydrin impurity & 104.6 & 110.9 \\
5 & Dichloro Impurity & 112.2 & 112.2 \\
\hline
\end{tabular}




\subsection{Robustness}

To evaluate the method robustness, different conditions of the method including the flow rate of the mobile phase and column oven temperatures were intentionally changed. The optimized flow rate of the mobile phase was $0.4 \mathrm{~mL} / \mathrm{min}$ and the same was altered from 0.36 to $0.44 \mathrm{ml} / \mathrm{min}$. The effect of column oven temperature on resolution was studied at $36^{\circ} \mathrm{C}$ and $44^{\circ} \mathrm{C}$ (altered by $4.0^{\circ} \mathrm{C}$ ). The results showed that there was no impact on chromatographic performance of all the impurities due to the mentioned changes proving the method robustness.

\subsection{Repeatability and Solution Stability}

The developed method was evaluated for repeatability by injecting six replicate injections at $1 \mathrm{ng} / \mathrm{ml}(0.5 \mathrm{ppm})$ mixture of five impurities and observed the \%RSD after including one bracketing standard. The acceptance criteria for \%RSD is less than $15 \%$. The RSD values achieved for all the five impurities are less than $7 \%$ which are well within the acceptance criteria which are captured in Table 4. Repeatability chromatogram for all the five impurities captured in Figure 9. The solution stability study of ranolazine and five impurities was evaluated by placing spiked and unspiked sample solutions at $25^{\circ} \mathrm{C}$ for $24 \mathrm{~h}$ and measured against freshly prepared standard solutions and there were no significant changes observed for any of the impurities. Therefore, we confirmed the stability of impurities in sample solution for at least 24 hours.

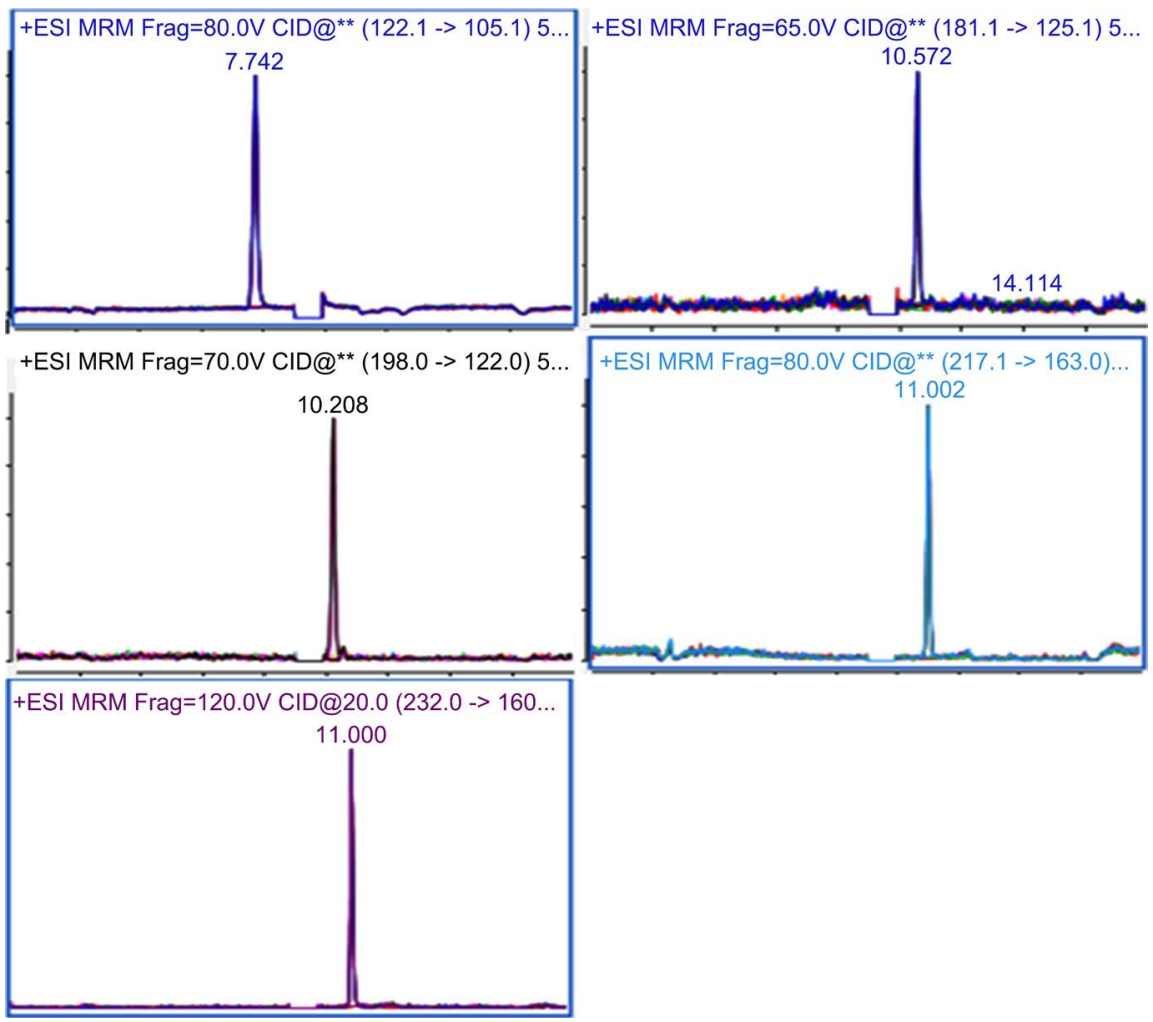

Figure 9. Repeatability overlay of seven injections including bracketing standard for all the five potential genotoxic impurities in Ranolazine. 
Table 4. Repeatability data for all the five impurities at $1 \mathrm{ng} / \mathrm{ml}(0.5 \mathrm{ppm})$ including bracketing standard.

\begin{tabular}{|c|c|c|c|c|c|c|}
\hline & S. NO & $\begin{array}{l}\text { Dimethyl aniline } \\
\text { Impurity }\end{array}$ & RCA Impurity & $\begin{array}{l}\text { Dimethyl phenyl } \\
\text { aminocarbonyl } \\
\text { chloride impurity }\end{array}$ & $\begin{array}{l}\text { Chlorohydrin } \\
\text { impurity }\end{array}$ & $\begin{array}{l}\text { Dichloro } \\
\text { Impurity }\end{array}$ \\
\hline & 1 & 35825 & 2127 & 2867 & 4426 & 3805 \\
\hline & 2 & 35597 & 2110 & 2567 & 4621 & 3635 \\
\hline \multirow{4}{*}{ Initial Replicates } & 3 & 35866 & 2296 & 2581 & 4472 & 3714 \\
\hline & 4 & 36557 & 2179 & 2879 & 4395 & 4083 \\
\hline & 5 & 36797 & 2414 & 3038 & 4415 & 4203 \\
\hline & 6 & 36404 & 2191 & 2999 & 4478 & 3912 \\
\hline \multirow[t]{4}{*}{ Bracketing standard } & 7 & 34417 & 2088 & 3015 & 4534 & 3986 \\
\hline & Average & 35923.3 & 2200.7 & 2849.4 & 4477.3 & 3905.4 \\
\hline & STD DEV & 794.2 & 116.6 & 199.3 & 78.7 & 202.7 \\
\hline & $\%$ RSD & 2.2 & 5.3 & 7.0 & 1.8 & 5.2 \\
\hline
\end{tabular}

\section{Conclusion}

In summary, the work presented here is novel in terms of simultaneous determination of multiple genotoxic impurities in ranolazine active pharmaceutical ingredient by single method using LC-MS/MS and there is literature available only for single impurity determination currently. We could also establish all the critical parameters to prove the method performance and done method validation as per ICH recommendations. The LOD and LOQ values determined for all five impurities are very low showing the high sensitivity performance of the method. The method is fully validated and presents good reproducibility, linearity, recovery and robustness. The method presented here could be very useful for the determination of five impurities in ranolazine during routine manufacturing process which will increase the throughput and could help in establishing the safety of the active pharmaceutical ingredient.

\section{Conflicts of Interest}

To the best of our knowledge this is the first method published for simultaneous determination of five potential genotoxic impurities in Ranolazine and the authors hold no conflicts to declare.

\section{References}

[1] USFDA, Guidelines for Industry (2008) Genotoxic and Carcinogenic Impurities in Drug Substances and Products: Recommended Approaches (Draft).

[2] United States Department of Health and Human Services, Food and Drug Administration (2008) Genotoxic and Carcinogenic Impurities in Drug Substances and Products: Recommended Approaches. 
[3] Note for Guidance on Pharmaceutical Development, EMEA/ CHMP/167068/2004. https://www.ema.europa.eu/en/human-regulatory/research-development/scientificguidelines/quality/quality-pharmaceutical-development।

[4] ICH M7 Assessment and Control of DNA Reactive (Mutagenic) Impurities in Pharmaceuticals to Limit Potential Carcinogenic Risk. https://database.ich.org/sites/default/files/M7_R1_Guideline.pdf

[5] Rayner-Hartley, E. and Sedlak, T. (2016) Ranolazine: A Contemporary Review. Journal of the American Heart Association, 5, No. 3. https://doi.org/10.1161/JAHA.116.003196

[6] Stone, P.H., Gratsiansky, N.A., Blokhin, A., Huang, I.Z., Meng, L., ERICA Investigators (2006) Antianginal Efficacy of Ranolazine When Added to Treatment with Amlodipine: The ERICA (Efficacy of Ranolazine in Chronic Angina) Trial. Journal of the American College of Cardiology, 48, 566-575.

https://doi.org/10.1016/j.jacc.2006.05.044

[7] Chaitman, B.R., Pepine, C.J., Parker, J.O., Skopal, J., Chumakova, G., Kuch, J., Wang, W., Skettino, S.L. and Wolff, A.A. (2004) Effects of Ranolazine with Atenelol, Amlodipine, or Diltiazem on Exercise Tolerance and Angina Tolerancy in $\mathrm{Pa}$ tients with Severe Chronic Angina. JAMA, 291, 309-316.

https://doi.org/10.1001/jama.291.3.309

[8] Suresh Babu, V.V., Sudhakar, V. and Murthy, T.E.G.K. (2014) Validated HPLC Method for Determining Related Substances in Compatibility Studies and Novel Extended Release Formulation for Ranolazine. Journal of Chromatography and Separation Techniques, 5, 1000209.

[9] Madhavi, A., Subba Rao, D.V., Srinivasu, P. and Naidu, A. (2009) Development and Validation of a New Analytical Method for the Determination of Related Components and Assay of Ranolazine in Bulk Drug and Pharmaceutical Dosage Forms by LC. Chromatographia, 70, 333-338. https://doi.org/10.1365/s10337-009-1145-5

[10] Sharma, T., Moitra, S.K., Si, S.C. and Sankar, D.G. (2011) Stability Indicating LC Method for the Determination of Ranolazine Hydrochloride in the Bulk Drug and in Pharmaceutical Dosage Form. International Journal of Pharmacy and Pharmaceutical Sciences, 3, 327-332.

[11] Khedkar, A.N., Veer, S.U., Rakh, M. and Rao, J.R. (2015) Stability Indicating Method Development and Validation of Ranolazine Hydrochloride in Bulk and Tablet Dosage Form by HPTLC. International Journal of Pharmaceutical and Clinical Research, 7, 77-83.

[12] Parvathareddy, S., Desam, N. and Nuthalapati, M.B.T. (2014) Development and Validation of Hplc and UV Methods for Estimation of Ranolazine in Bulk and Marketed Formulation. International journal of Innovative Pharmaceutical Sciences and Research, 2, 1042-1058.

[13] Patel, R.C., Rathod, D.K., Patel, P.R. and Patel, V.S. (2010) Estimation of Ranolazine Hydrochloride by Spectrophotometric and RP-HPLC in Tablet Dosage Forms. International Journal of Pharmaceutical and Applied Sciences, 1, 79-83.

[14] Tian, L., Jiang, J.J., Huang, Y.L., Hua, L., Liu, H. and Li, Y.S. (2007) Sensitive Quantification of Ranolazine in Human Plasma by Liquid Chromatography-Tandem Mass Spectrometry with Positive Electrospray Ionization. Journal of Chromatography B, 846, 346-350. https://doi.org/10.1016/j.jchromb.2006.08.010

[15] Bai, S., Gao, H., Qu, H., Liang, Y., Li, Y., Zheng, Z., Wang, X. and Hao, G. (2011) Quantitative Determination of Ranolazine in Human Plasma by High Performance Liquid Chromatography-Tandem Mass Spectrometry. Northwest Pharmaceutical 
Journal, No. 4, 249-251.

[16] Zhao, L., Li, H., Jiang, Y., Piao, R., Li, P. and Gu, J. (2008) Determination of Ranolazine in Human Plasma by Liquid Chromatographic-Tandem Mass Spectrometric Assay. Journal of Chromatographic Science, 46, 697-700.

https://doi.org/10.1093/chromsci/46.8.697

[17] Dev, R., Tyagi, A., Kumar, R., Kumar, P., Kumar, A., Bhargava, S., Prakash, A. and Singh, R. (2019) Method Development and Validation of 2-[(2-Methoxyphenoxy) Methyl] Oxirane Content in Ranolazine Drug Substance by LC-MS/MS. Journal of Chemistry and Chemical Sciences, 9, 214-225. 